\title{
Influence of the Moisture Content on the Flowability of Blast Furnace Dust
}

\author{
Christof Lanzerstorfer \\ Process Engineering and Production/University of Applied Sciences Upper Austria \\ Stelzhamerstraße 23, Wels, Austria \\ c.lanzerstorfer@fh-wels.at
}

\begin{abstract}
In this paper the influence of the moisture content on the flow characteristics of blast furnace dust is investigated. The flowability of granular material is essential for the design and operation of dust separators, transport equipment and storage silos. Two blast furnace dust samples from different blast furnaces were investigated. The moisture content was adapted for measurement with the shear tester by adding water to the dried blast furnace dust samples. The measurement showed a significant decrease in flowability at higher moisture content of the dust samples. The bulk density of the dust samples was lower at higher values of the moisture content. For the finer blast furnace dust the wall friction angles increased with the moisture content, while for the coarser blast furnace dust a decrease in the wall friction angles was observed for low moisture content. At higher moisture content the wall friction angle increased with the water content.
\end{abstract}

Keywords: Blast furnace, dust, moisture content, flowability

\section{Introduction}

Iron and steel are still the most important commercial metals. The annual production in Germany of steel and pig iron in 2014 was 42.9 Mio t and 27.9 Mio. t, respectively [1]. The blast furnace (BF) serves to produce pig iron from iron ore. The shaft of the BF is filled continuously from the top with layers of iron-bearing materials (iron ore, sinter, pellets, etc.) and coke. In order to reduce the iron oxides by carbon monoxide, heated air is fed into the BF in a counter-current flow. The reaction of oxygen with the coke to carbon monoxide also supplies the required heat for the process. The reduction gas leaves the BF as top gas. This dust containing gas can be used as a fuel after removal of the dust because of its heating value. The separation of the dust is performed in two stages. First, the coarse dust is collected in a dry dust separator (a dust catcher or a cyclone). In a second separation step the remaining fine dust is collected, usually by a venturi scrubber or an annular gap scrubber. In some BFs an electrostatic precipitator or a fabric filter is installed as a second de-dusting stage.

The dust collected in the first-stage dust separator consists mainly of iron oxides $(15 \%-40 \% \mathrm{Fe})$ and coke particles $(25 \%-40 \%$ C) which are fine enough to be carried by the discharged gas [2]. Minor constituents are calcium oxide, aluminium oxide and silica [2-4]. The mass median diameter of dust catcher dust is typically in the range of $100-200 \mu \mathrm{m}$. Therefore, the BF dust is usually recycled to the sinter plant $[5,6]$ to recover the valuable components. The average amount of dust separated in the first-stage dust catcher of European BFs is $18 \mathrm{~kg}$ dust per ton of hot metal produced [2]. The dust has to be discharged from the dust separator, transported and stored. For smooth operation of these processes the flow properties of the material are crucial. The flowability of fine granular material depends on several properties: grain size, grain size distribution and grain shape $[7,8]$. The moisture content of the material also has a significant influence on the flow properties. Increasing moisture content leads to reduced flowability because of the increasing influence of the liquid bridges between the particles and the resulting capillary forces $[9,10]$. At high moisture content, when the pores between the particles are filled with water, the particles form a suspension in water and the cohesive forces decrease $[9,11,12]$. However, this effect cannot be observed with all materials [13]. The flow properties of dust catcher dust have been investigated in a recent study [14]. The flowability of the dry dust catcher dusts has been reported to be very good.

In this study the influence of the moisture content on the flowability of BF dust was investigated. Measurements with BF dusts from two different blast furnaces were performed. The flowability at increased water content is important because the dust is often wetted to avoid dust generation during handling and storage of the material. 


\section{Material and Methods}

$\mathrm{BF}$ dust samples from two different plants were collected. The material was dried in a compartment drier for twentyfour hours. For production of dust samples with various water contents an Erweka AR 403/SW 1/S plough-share drum mixer was used. In the mixer the dried BF dust was mixed with the appropriate amount of water. The speed of the mixer was $300 \mathrm{rpm}$ and the mixing time was 5 minutes. The moisture content of the samples was determined gravimetrically with a Sartorius infrared moisture analyser MA35M at $105^{\circ} \mathrm{C}$.

For measurement of the particle size distribution of the iron ore concentrate a laser diffraction instrument with dry sample dispersion from Sympatec, type HELOS/RODOS, was used.

The yield locus was determined using a Schulze ring shear tester, type RST-XS, with a $30 \mathrm{~cm}^{3}$ shear cell. The bulk density of the material in dependence of the consolidation stress was also determined. The wall yield locus was determined using a Schulze ring shear tester, type RST-XS, with a wall friction shear cell, where the bottom ring of this cell is formed by a sample of structural steel S235JR (1.0038).

A quantitative characterization of the flowability of a dust can be given by $\mathrm{ff}_{\mathrm{c}}$ which is the ratio of the consolidation stress $\sigma_{1}$ to the unconfined yield strength $\sigma_{\mathrm{c}}[15]$. The larger the $\mathrm{ff}_{\mathrm{c}}$, the better a granular material flows. The consolidation stress is equal to the major principal stress of the Mohr stress circle which is tangential to the yield locus and runs through the point of steady-state flow. The unconfined yield strength results from the stress circle which is tangential to the yield locus and runs through the origin [16]. The usual classification used to define flow behaviour consists of five categories: not flowing: $\mathrm{ff}_{\mathrm{c}}<1$; very cohesive: $1<\mathrm{ff}_{\mathrm{c}}<2$; cohesive: $2<\mathrm{ff}_{\mathrm{c}}<4$; easy-flowing: $4<\mathrm{ff}_{\mathrm{c}}<10$ and free-flowing: $10<\mathrm{ff}_{\mathrm{c}}$ [15]. The flowability of a granular material often depends on the consolidation stress. For many powders better flowability will be achieved at a higher consolidation stress. This can be visualized best in a diagram showing the unconfined yield strength dependent upon the consolidation stress when the diagram also includes lines of constant $\mathrm{ff}_{\mathrm{c}}$ ratio [15]. Logarithmically scaled axes improve the representation of the results in the diagram [17].

\section{Results and Discussion}

The particle size distributions of the two BF dusts investigated are given in Figure 1. The mass median diameters of dust BF1 and dust BF2 were $99 \mu \mathrm{m}$ and $204 \mu \mathrm{m}$, respectively. Thus, the two dusts covered the reported typical size range for BF dusts [14].

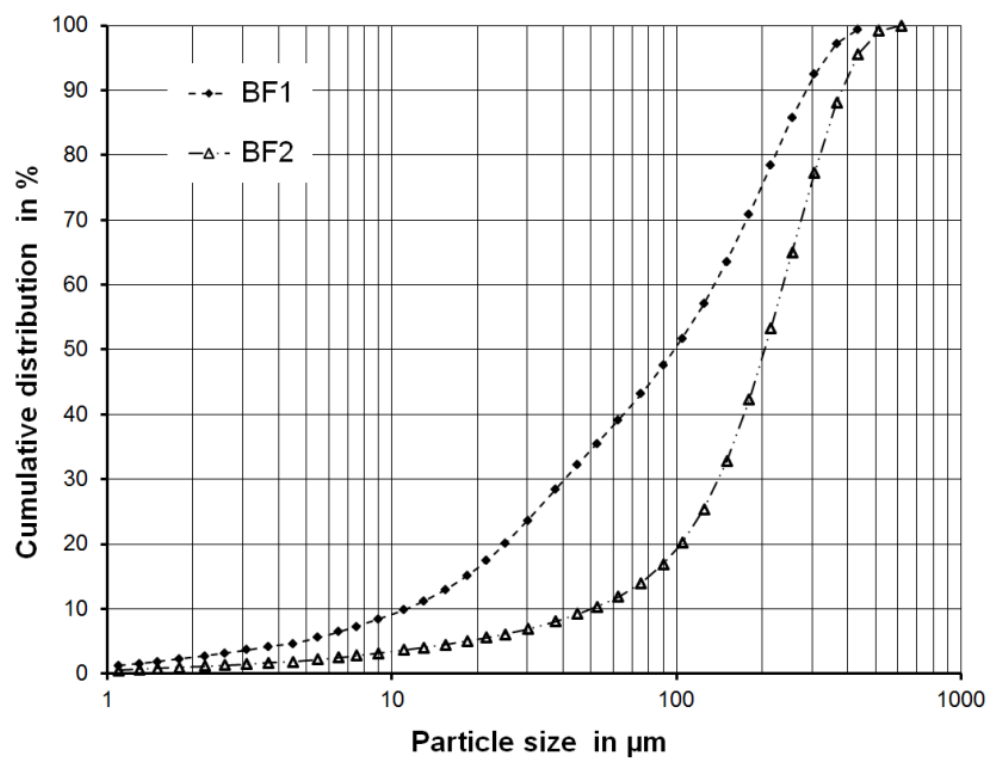

Fig. 1: Particle size distribution of BF dust $\mathrm{A}$ and $\mathrm{B}$.

Figure 2 shows the bulk density of the BF dusts for two values of the normal stress as a function of the moisture content. Generally, the bulk density of BF dust BF2 is lower. The reason for the lower density is the lower iron content and the higher carbon content of this dust. As one would expected, the bulk density is higher at higher values of the normal stress. With increasing moisture content the value of the bulk density decreases. 


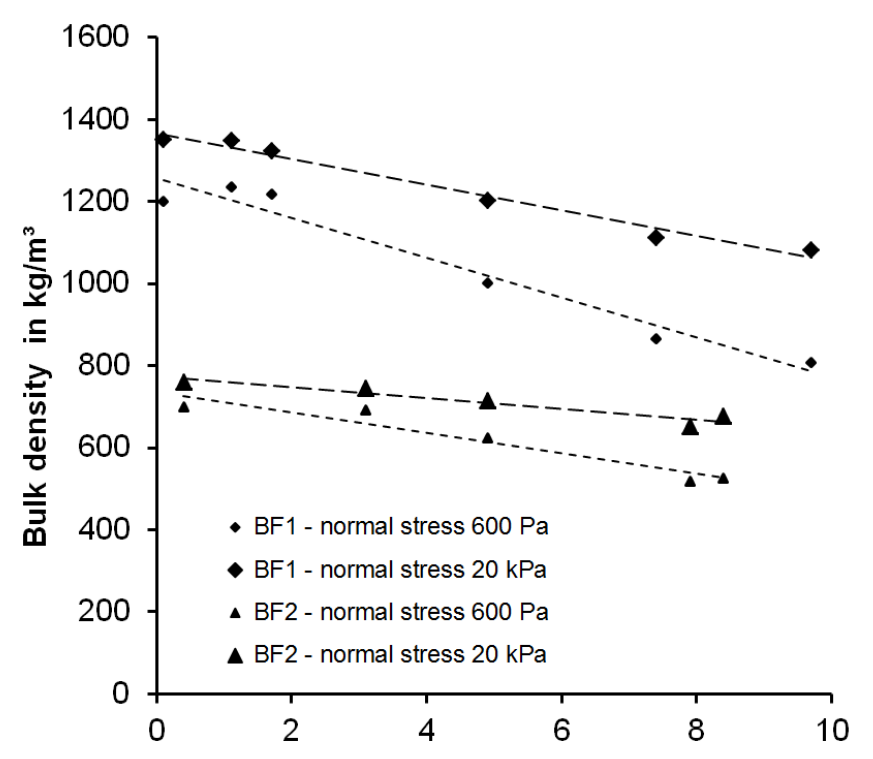

Moisture content of the blast furnace dust in $\%$

Fig. 2: Bulk density as a function of the moisture content.

Both BF dusts are easy-flowing at low values of the consolidation stress. For both dusts the flowability improves to free-flowing at higher values of the consolidation stress. This is depicted on the right in Figure 3 for BF dust BF1 and for BF dust BF2 on the left in Figure 3. Increasing moisture content reduces the flowability of the BF dust. At a moisture content of approximately $7 \%$ the flowability is very cohesive for low values of the consolidation stress. At higher values of the consolidation stress the flowability improves to cohesive.
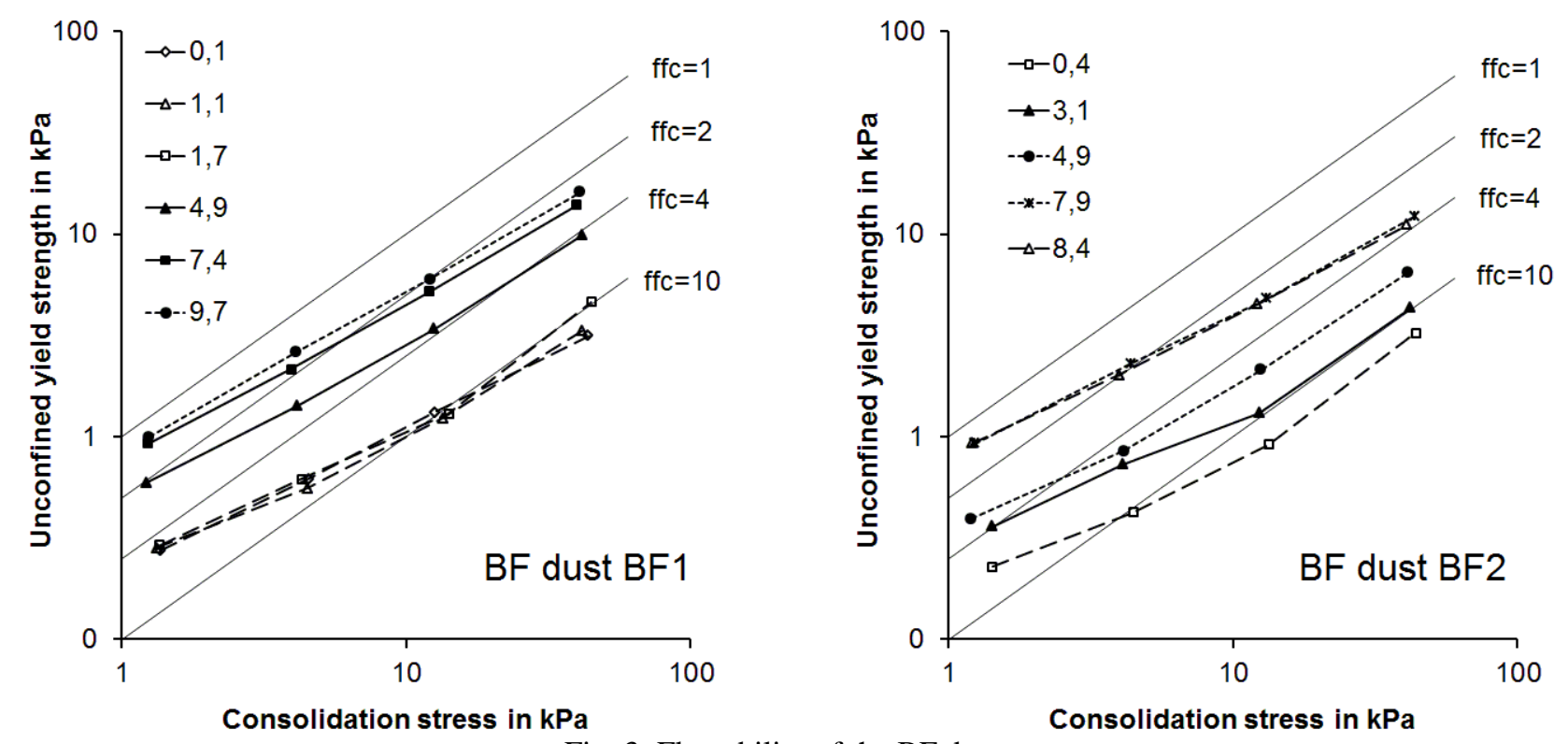

Fig. 3: Flowability of the BF dusts.

Figure 4 shows the flowability in dependence of the moisture content. Generally, the flowability of BF dust BF2 is slightly better. This can be attributed to the coarser particle size. The clear trend of decreasing flowability with the moisture content ends at about $8 \%$ moisture content. For the samples with a higher moisture content the flowability was nearly constant. 


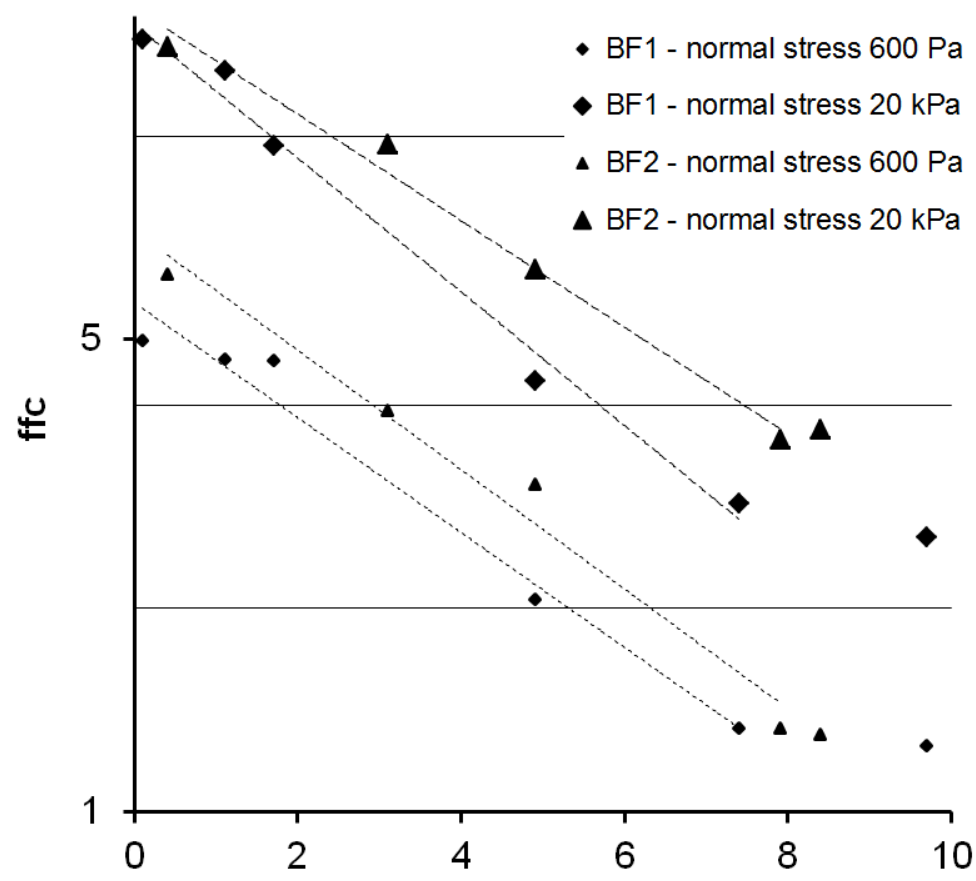

Moisture content of the blast furnace dust in \%

Fig. 4: Particle size distribution of the BF dusts BF1 and BF2.

The wall friction angles also decreased with increasing stress (Figure 5). When the axis for the wall normal stress is in a logarithmic scale the decrease of the wall friction angle nearly follows a straight line. For BF dust BF1 the wall friction angles increased with increasing moisture content while for the coarser BF dust BF2 the wall friction angle first decreased with increasing moisture content. The lowest wall friction angles for this dust were measured at a moisture content of $4.9 \%$. At higher values of the moisture content the wall friction angles increased again.
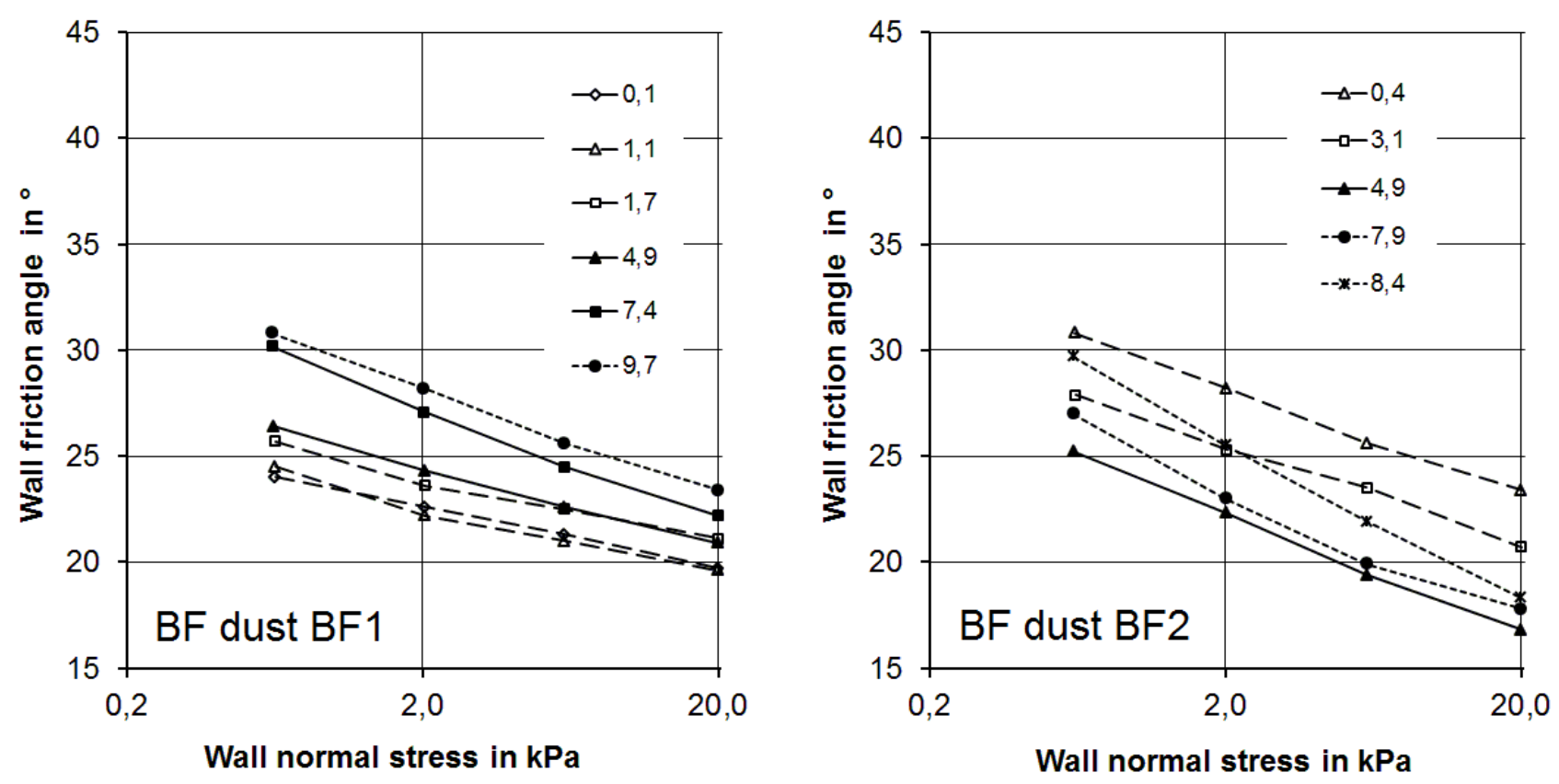

Fig. 5: Wall friction angle of the BF dusts BF1 and BF2. 


\section{Conclusion}

Generally, the flowability increases with higher values of the stress. The value of the wall friction angle decreases with higher values of the stress.

In the range of $0 \%$ to $8 \%$ moisture content the flowability of BF dust decreases with increasing moisture content while between $8 \%$ and $10 \%$ moisture content the flowability was more or less constant. The bulk density also decreases with increasing moisture content.

In the range of $0 \%$ to $10 \%$ moisture content the wall friction angle of the finer BF dust increases. For the coarser $\mathrm{BF}$ dust the dependence of the wall friction angle is different: at low moisture content the wall friction angle decreases with increasing moisture content while at a moisture content of approximately $>5 \%$ the wall friction angle increases again.

\section{Acknowledgements}

Proofreading by P. Orgill and laboratory work by T. Frankenberger are gratefully acknowledged.

\section{References}

[1] "Deutschland: Stahlproduktion," stahl eisen, vol. 135, no. 2, p. 71, 2015.

[2] R. Remus, M. A. Aguado-Monsonet, S. Roudier, and L. D. Sancho, "Best Available Techniques (BAT) Reference Document for Iron and Steel Production," Industrial Emissions Directive 2010/75/EU, Integrated Pollution Prevention and Control, Luxembourg: Publications Office of the European Union, 2013.

[3] B. Das, S. Prakash, P. S. R. Reddy, and V. N. Misra, "An overview of utilization of slag and sludge from steel industries," Resour. Conserv. Recy., vol. 50, no. 1, pp. 40-57, 2007.

[4] M. Więcek and J. Mróz, "Characteristics of fine-grid iron-bearing materials - dusts, sludges, mill-scale sludges," in Acta Metall Slovaca Conf., vol. 4, pp. 106-113, 2014.

[5] R. Hansmann, P. Fontana, A. Chiappero, I. Both, and J.-L. Roth, "Technologies for the optimum recycling of steelmaking residues," stahl eisen, vol. 128, no. 5, pp. 29-35, 2008.

[6] C. Lanzerstorfer, B. Bamberger-Straßmayr, and K. Pilz, "Recycling of blast furnace dust in the iron ore sinter process: investigation of coke breeze substitution and the influence on off-gas emissions," ISIJ Int., vol. 55, no. 4, pp. 758-764, 2015.

[7] G. Lumay, F. Boschini, K. Traina, S. Bontempi, J.-C. Remy, R. Cloots, and N. Vandewalle, "Measuring the flowing properties of powders and grains," Powder Technol., vol. 224, pp. 19-27, 2012.

[8] D. Schulze, Pulver und Schüttgüter. Fließeigenschaften und Handhabung, Berlin: Springer-Verlag, 2006.

[9] D. Schulze and J. Schwedes, "Das Fließverhalten und die Silolagerung von REA-Gips," Chem. Ing. Tech., vol. 63, no. 3, pp. 256-275, 1991.

[10] E. Teunou and J.J. Fitzpatrick, "Effect of relative humidity and temperature on food powder flowability," J. Food Eng., vol. 42, no. 2, pp. 109-116, 1999.

[11] I. A. S. Z. Peschl, "Quality Control of Powders for Industrial Application,” powder handling process, vol. 1, no. 4, pp. 357-363, 1989.

[12] H. Rumpf, Particle Technology, New York: Chapman and Hall, 1990.

[13] J. J. Fitzpatrick, K. Barry, P. S. M. Cerqueira, T. Iqbal, J. O. Neill, and Y. H. Roos, "Effect of composition and storage conditions on the flowability of dairy powders," Int. Dairy J., vol. 17, no. 4, pp. 383-392, 2007.

[14] C. Lanzerstorfer, "Mechanical properties of dust collected from blast furnace dust catchers and cast house de-dusting filters," Particul. Sci. Technol., 2015.

[15] D. Schulze, "Measuring powder flowability: A comparison of test methods. Part I," Powder Bulk Eng., vol. 10, no. 4, pp. 45-61, 1996.

[16] A. W. Jenike, Storage and flow of solids, Bulletin 123, Salt Lake City: Engineering Experiment Station, University of Utah, 1964.

[17] C. Lanzerstorfer, "Flowability of various dusts collected from the off-gases of a secondary copper smelter," Particuology, vol. 25, pp. 68-71, 2016. 